\title{
JIPES
} Journal of Indonesian Physical Education and Sport

P-ISSN 2442-4900 | E-ISSN 2461-1271

Vol. 6, No.2, December 2020, page 26-35

\section{Effects of Anthropometric Variables on Sport Performance of Male University Champion-Handballers in West Africa}

\author{
${ }^{1}$ Bakinde Surajudeen Tosho \\ Department of Human Kinetics Education, Faculty of Education, University of Ilorin. \\ *Corresponding author email: bakinde41@gmail.com
}

\begin{abstract}
This study focused on the effects of anthropometric variables on male handball champions in West Africa. An ex-post facto research design was adopted. The population of all male handball players in the West African University Games (University of Ilorin; University of Ghana and University of Abomey-Calavi) were participants in the study. Two research instruments were adopted in this study this includes measuring tape and a standard handball court. Census sampling technique was used to select all 37 players available during the contest. Census method is the method of statistical enumeration where all members of the population are studied. These players composed of (Wrist $(\mathrm{cm}) 18.88$, Chest $(\mathrm{cm}) 17.78$, mid-thigh $(\mathrm{cm})$ 18.35, Wrist $(\mathrm{cm})$ 91.96, Chest $(\mathrm{cm})$ 95.02, mid-thigh 89.83, Wrist $(\mathrm{cm})$ 49.37, mid-thigh 55.04, Wrist $(\mathrm{cm})$ 49.26). To test a substantive difference between the groups determined at 0.05 alpha significant levels, descriptive and inferential statistics for $\mathrm{t}$ test and ANOVA Scheffe post hoc, multiple comparison tests were adopted. The results of this study showed that men players had considerable differences in anthropometric measurements. As the men's players were significantly different in the handle circumference $(f=4.624>3.32(0.05)$ df36); chest circumference $(f=.750<3.32(0.05)$ df36). Coaches were recommended to focus on these variables in selecting and coaching processes (Wrist circumference, Chest curvature, Thigh). This study also recommends that this profiling should be adopted in players' selection and the development of sport specific programs.
\end{abstract}

Keywords: Anthropometric, Performance, Wrist girth.

\section{INTRODUCTION}

Anthropometry is the anthropology branch that concerns with comparative measurements of the human body composition and its type. Anthropometrics is the process of measuring dimensions of the human body, and these measurements are then used to either describe size and proportion or to indirectly estimate body compositions (Toriola, 1999; Ajayi-Vincent, 2005; Dominic, 2011; Dominic, 2006). In another view, Anthropometry is a research area within physical ergonomics that is concerned with body measurements such as body size, shape, strength, mobility, flexibility and work capacity. The use of anthropometric data is often a fundamental part of the process to achieve a good fit between humans' capabilities and the design of products or workplaces.

Anthropometrical variables include body composition and anaerobic performance variables, have been tested in sports to evaluate the impact of training and to provide information to 


\section{JIPES}

coaches to select young players, to distinguish the demands of different competition levels and of different sports (Ugarkovic, Matavulj, Kukolj and Baric, (2002), Lidor, Falk, Amon, Cohen and Segal, 2005). In studies with pre-pubertal children researchers (Baxer-Jones, Helms, Maffulli, Baines-Preece and Preece, (1995), Damsgaard, Bencke and Matthiesen (2000) did not determine an effect of training on body composition, anthropometrical parameters or pubertal development, confirming that children in competitive sports are selected due to constitutional factors.

The physique's role is very important in the viewpoint that morphological constitutions and its proportions in the human body are genetically determined, and it can not be changed under normal circumstances Sodhi (1991). It is believed that physical fitness is a trainable factor. Still, the influence of one's physique and body composition seem to play a great role in its determination as high-level performance is only possible in an individual with good genetic predisposition and under optimal environmental conditions. Studies have revealed that champions of different sports such as throwing, walking, jumping and running require different body proportions concerning their events (Tanner, 1964, De Garry, Levine, Carter(1974: Carter, Ross, Aubry, Hebbelinck and Borms(1982); Sharma, 1982; Luthra and Shaw, 1990; Sidhu et al. 1990, Vikram, Vijay, 2010, Toriola, 1999, Granados, Izquierdo, Ibanez, Bonnabau and Gorostiaga, 2007). Hasan et al. :(2007) and Dominic, 2006: Agbonjimi, 1985: Reilly, Seecher, Small and William, (1997).

On the other side in literature, body composition and some anthropometrical variables provide an advantage in certain sports (Van den Tillar \& Ettema 2004, Gabbett, Georgieff, Anderson, Cotton, Savovic, Nicholson (2006)). In sport arena, such as a basketball, tallness is an advantage (Carter, Ackland, Kerr, Stapff (2005), and more powerfull built players have an advantage in handball (Gorostiaga, Granados, Ibanez, Izquierdo, 2005, Granados, et al.; 2007). Simultaneously, training at a competitive level is influenced by children's and adolescents' motor abilities, Maffulli, king, helms (1994, Gorostiaga, lzquiedo, lturralde, Ruesta, lbanez, 1999).

Anthropometric provides us with the foundations and private information concerning motor variables, which is to reach a high level of performance and achievement. They are measurable on the components of fat, muscles, and bones to give the coaches a specialized vision to select athletes to achieve high athletic performance levels. Mohammed, (2010), Mahmoud, (2005), Young, Newton, Doyle, Chapman, Cormack and Stewart, (2005), Pyne, Gardner, Sheeham and Hopkins, (2006), McIntyre, (2005); McIntyre \& Hall, (2005), Bale, (1986), Duthie, Pyne \& Hooper, (2003), Gabbett, (2000), McGee Burkett, (2003), Garstecki, Latin and Cuppett, (2004), Norton and Olds, (1996), Ye, (1995). Optimum anthropometric variables were taken into account as a precondition for good sport performance. Studies have identified a particular type of body (Carter, 1970; Hirata, 1966) likely to lead to selected sporting events (Sharma \& Dixit, 1985). Xu and Chen (2000) reported that China's main anthropometric factors were stature and arm length, highly interrelated by elite female aerobic athletes. The main physical performance tests linked to sports performance were 


\section{JIPES}

chin-up and long jumping. This study indicates that aerobics' performance is strongly correlated with anthropometric indexes and physical performance, such as stature, arm length, chin-up, and long-standing jump (Xu \& Chen, 2000). Sub elite and elite rugby-league anthropometry variables give insights into the factors that can limit and contribute to high performance (Gabbett, Georgieff, Anderson, Cotton, Savovic, \& Nicholson, (2006), Meir et al , (2001), O'Connor, (1996).

Concerning the relation between an anthropometric variable and $100 \mathrm{~m}$ sprinter performance, an anthropometric variable such as stature, trochanteric-tibial lateral length and thigh circumference has been reported to have significant effects on achievement, while body mass and calf girth do not have a significant relationship to achievement (O'Connor, (1996); Meir, Newton and C. The above literature shows that in sporting events such as aerobics, walking and sprinter, athletes' anthropometric variables and their physical performance interact. The previous studies of the athletes of certain sporting events have led us to assume that certain correlations exist between the anthropometric variables, physical performance, and volleyball players' achievement. From the point of view of physical performance, handball is an intermittent and complex sports game that is played over 60 minutes, requiring maximum effort over a short period of time, with players jumping, running and throwing the ball high speed and low intensity recovery periods. Handball is an Olympic sport which has been played since the 1972 Munich Games with other major international competitions, including world championships, continental championships, and international tournaments. From the point of view of physical performance, handball is an intermittent and complex sports game that is played over 60 minutes, requiring maximum effort over a short period of time, with players jumping, running and throwing the ball high speed and low intensity recovery periods. Clearly, it requires significant physical preparation in order to compete successfully, given the physical challenges of the game (Ziv and Lidor, 2009; Moncef et al., 2012). To some extent, handball performance is influenced by the anthropometric characteristics of athletes and it is possible that such characteristics distinguish players from a different level of competition (Chaouachi et al., 2009; Milanese et al., 2011). In order to maximize performance on the playing field, it has been proposed that each specific position in handball requires unique physiological and physical attributes relating to the technical and tactical requirements of each position (Vila et al., 2012; Chaouachi et al., 2009). Therefore, this study analyzed the anthropometric characteristics of each handballer in West Africa.

\section{METHOD}

This study adopted ex-post facto research, with a consent form signed for ethical consideration by all the handballers representing their universities at the 13th West Africa Games (WAUG) who volunteered for this study. Census of all 37 players participated in the contest were sampled. Three universities were sampled, each with a handball team consisting of 12 participants. Census method is the method of statistical enumeration where all members of the population are studied. All the players had official medical clearance approved by the 
WAUG accreditation committee (the University of Ilorin, University of Ghana and UAC Benin). Standardized instruments and services included the study's equipment: measuring tape and a standard handball court. Data collection was achieved by taking the subjects' measurements and documenting the outputs in the relevant columns. In the respondent's measurements, researchers and two qualified research assistants were used in compliance with the guidelines specified for the conduct of the research. Measurements of Anthropometric Characteristics.

\section{Statistical Analysis}

Descriptive statistics were used to determine the differences in the anthropometric characteristics of the players. Mean, Range and Standard Deviation were used to analyzed the anthropometric characteristics of the players. Mean, range and standard deviation were used to determine the differences in the anthropometric characteristics of the players. Inferential statistic was used to determine the significant differences among the anthropometric characteristics of the players . Inferential statistics helps to specifically determine significant differences among variables and draws conclusion on them. Hence, Analysis of variance (ANOVA) was used to determine the significant difference among the anthropometric characteristics of the players, Scheffe post hoc analysis on the effects of anthropometric sport performance variables among the universities was also conducted at 0.05 level of significant with the aid of Statistical Product for Service Solutions (SPSS) to clearly shows the direction of the significant difference among the players.

\section{Wrist girth (cm):}

Anatomical: The subject assumed a relaxed standing position with the left arm hanging by the side.

Procedure: The subject's right arm was slightly flexed at the shoulder, the elbow is extended, the forearm supinated and the hand relaxed. This girth measurement was taken distal to the styloid processes. It is the minimum girth in this region. Manipulation of the tape measure is required to sure the minimal girth is obtained.

\section{Chest Girth (cm):}

Anatomical site: this girth was taken at the level of the mesosternale.

Procedure: With arms hanging from the sides and slightly abducted, the subject assumed a relaxed standing position. The researcher stood to the subjects' right, abducting the arms to the horizontal position, enabling the tape to move around the thorax. The tape stub and the housing were both held in the right hand while the left hand was used by the anthropometrist to adjust the level of the tape at the back to the adjudicated level of the marked mesosternale. With the left hand, the anthropometrist resumed control of the snub and positioned the tape in front at the level of the marked mesosternale using the cross-hand technique. The subject was instructed to lower their arms, with the arms slightly abducted, to a relaxed position. To ensure that it has not slipped and does not overly indent the skin, the tape was then re- 


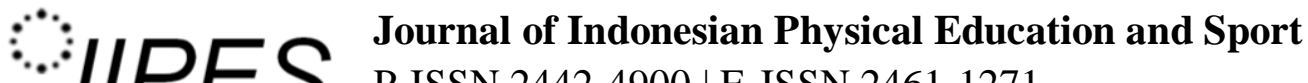 \\ P-ISSN 2442-4900 | E-ISSN 2461-1271 \\ Vol. 6, No.2, December 2020, page 26-35}

adjusted as necessary. The subject respires normally and the measurement was taken at the end of the normal (end tidal) expiration.

\section{Mid-Thigh girth(cm):}

Anatomical: This is the right mid-thigh girth at the marked mid-trochanterion-tibiale-laterale site

Procedure: A relaxed standing position with arms folded across the thorax was assumed by the subject. The subject's feet were separated with the weight evenly distrusted. Passing the tape between the lower thighs, the anthropometrist then slides the tape to the correct plane. The tape snub and the housing were both held in the right hand, while the left hand was used by the anthropometrist to adjust the tape level to the target level.

\section{RESULTS AND DISCUSSION}

The anthropometrist used the cross-hand technique to resume control of the stub with the left hand, positioning the tape so that it was held in a perpendicular plane. The tape was then readjusted as necessary to ensure that the skin did not slip and not indent excessively. Measurements to the nearest $0.1 \mathrm{~cm}$ were taken.

Table 1: Descriptive statistics on Effects of Anthropometric sport performance variables and among University champion-handballers in West Africa.

\begin{tabular}{|c|c|c|c|c|c|c|c|c|c|c|c|c|c|c|c|c|}
\hline \multirow[t]{2}{*}{ Variables } & \multicolumn{3}{|c|}{ A(Benin) } & \multicolumn{5}{|c|}{ B(Ghana) } & \multicolumn{3}{|c|}{ C(Ilorin) } & \multicolumn{4}{|c|}{ Total (ABC) } & \multirow[b]{2}{*}{ Range } \\
\hline & $\mathbf{N}$ & $\mathbf{x}$ & SD & Range & $\mathbf{N}$ & $\mathbf{X}$ & SD & Range & $\mathbf{N}$ & $\mathbf{X}$ & SD & Range & $\mathbf{N}$ & $\mathbf{X}$ & SD & \\
\hline Wrist girth $(\mathrm{cm})$ & 13 & 18.88 & .834 & $17.3-20.7$ & 12 & 18.35 & .757 & $\begin{array}{l}18.4- \\
19.5\end{array}$ & 12 & 17.78 & 1.09 & $16-18.7$ & 37 & 18.35 & .99 & $16-20.7$ \\
\hline Chest girth $(\mathrm{cm}$ & 13 & 91.96 & 4.94 & $83.7-102.3$ & 12 & 95.02 & 1.76 & $\begin{array}{l}39.5- \\
102.6\end{array}$ & 12 & 89.83 & 4.23 & $\begin{array}{l}84.5- \\
98.7\end{array}$ & 37 & 92.26 & 1.06 & $\begin{array}{l}39.5- \\
102.6\end{array}$ \\
\hline $\begin{array}{l}\text { Mid-thigh } \\
\text { girth }(\mathrm{cm})\end{array}$ & 13 & 49.37 & 5.33 & $43.7-61.5$ & 12 & 55.04 & 2.34 & $\begin{array}{l}51.5- \\
59.4\end{array}$ & 12 & 49.26 & 4.51 & $\begin{array}{l}42.5- \\
51.5\end{array}$ & 37 & 51.17 & 4.97 & $\begin{array}{l}42.5- \\
61.5\end{array}$ \\
\hline
\end{tabular}

Table one, presents the means and standard deviations results of the effects of Anthropometric sport performance variables for the male university champion- handballers. There are variations in the range values among the University champion male handballers in wrist girth, chest girth, and Mid-thigh girth. This could suggest that the game of handball might be suitable for individuals within a wide range of anthropometric variables. This could also suggest the suitability of handball game to wide variations of anthropometric performance variables values. That may also mean that handball game allows a wide range of values in anthropometric variables to be champion players.

Table 2: The summary of Effects of Anthropometric sport Performance variables for the University Male Champion-Handballers in West Africa

\begin{tabular}{|c|c|c|c|c|c|c|c|}
\hline Variable (units) & Source of variation & Sum square & Df & Mean square & Fratio & Fcal.val & Decision \\
\hline \multirow{4}{*}{ Wrist girth $(\mathrm{cm})$} & Between Groups & 7.568 & 2 & 3.784 & & & \\
\hline & Within Groups & 27.824 & 34 & .818 & 4.624 & 3.32 & $\mathrm{R}$ \\
\hline & Total & 35.392 & 36 & & & & \\
\hline & Between Groups & 162.953 & 2 & 81.477 & & & \\
\hline
\end{tabular}




\section{JIPES} Journal of Indonesian Physical Education and Sport

P-ISSN 2442-4900 | E-ISSN 2461-1271

Vol. 6, No.2, December 2020, page 26-35

\begin{tabular}{lllllll} 
Chest girth $(\mathrm{cm})$ & Within Groups & 3927.451 & 34 & 115.513 & .705 & 3.32 \\
& Total & 4090.404 & 36 & & A(NR) & \\
& Between Groups & 265.144 & 2 & 132.572 & 7.220 \\
Mid-Thigh & Within Groups & 624.259 & 34 & 18.361 & 3.32 \\
girth $(\mathrm{cm})$ & Total & 889.403 & & & $\mathrm{R}$ \\
\hline
\end{tabular}

Table two is the analysis of variance (ANOVA) on the effect of anthropometric sport performance variables of male university champion-handballers in West Africa. The revealed confirmed that there were significant differences in the anthropometric performance variables among the university players in wrist girth, mid-thigh girth. However, variables such as chest girth were not significant at 0.05 level of acceptance.

Table 3: Scheffes post hoc tests results on the Effects of Anthropometric Sport performance variables among male University champion-handballers in West Africa.

\begin{tabular}{llllll}
\hline Variables (units) & Indep & Dep & $\begin{array}{l}\text { Mean } \\
\text { Difference }\end{array}$ & S & Sig. \\
\hline Wrist girth(cm) & UACBenin & Uni-Ghana & .534 & .362 & .348 \\
& & & 1.10 & .362 & .017 \\
& Uni-llorin & & -5.66 & 1.71 & .009 \\
Mid-thigh & UACBenin & Uni-Ghana & & & \\
girth(cm) & & & .11 & 1.71 & .998 \\
& Uni-llorin & & & & \\
\hline
\end{tabular}

The table three, presents the Scheffe post hoc analysis on the effects of anthropometric sport performance variables among the universities result which clearly showed where the significant differences exists among the players from participating universities. The scheffe post hoc showed that the University of Ilorin Male Handballers were significantly different from the other universities handballers in wrist girth, mid-thigh girth. Noteworthy also is the fact that University of Abomey-Calavi Benin and University of Ghana were significantly similar in wrist girth, mid-thigh girth. Further from this table, handball players from UACBenin were significantly different from players of other participating universities in Wrist girth, mid-thigh girth.

Table 4: Summary of Item by Item analysis of Effects of Anthropometric sport performance variables among male university champion -handballers in West Africa.

\begin{tabular}{|c|c|c|c|c|c|}
\hline \multirow{2}{*}{$\begin{array}{l}\text { Anthropometric and motor variables } \\
\text { performance (units) }\end{array}$} & $1^{\text {st }}$ Position & \multicolumn{2}{|l|}{$2^{\text {nd }}$ Position } & \multicolumn{2}{|l|}{$3^{\text {rd }}$ Position } \\
\hline & UACBenin & Uni-Ghana & $X$ & Uni-llorin & $X$ \\
\hline Wrist girth $(\mathrm{cm})$ & 18.88 & 18.35 & & 17.78 & \\
\hline Chest girth $(\mathrm{cm})$ & 91.96 & 95.02 & & 89.83 & \\
\hline Mid-thigh girth $(\mathrm{cm})$ & 49.37 & 55.04 & & 49.26 & \\
\hline
\end{tabular}




\section{JIPES}

Journal of Indonesian Physical Education and Sport

P-ISSN 2442-4900 | E-ISSN 2461-1271

Vol. 6, No.2, December 2020, page 26-35

\section{Discussion of finding}

Wrist girth $(\mathbf{c m})$ : The mean wrist girth for the Male handballer is $18.35 \pm .99$ and a range of $16-20.7 \mathrm{~cm}$. The F-ratio of 4.624 (table 2$)$ is statistically significant at $0.05(\mathrm{~F}-0.05=3.32)$. The null hypothesis that stated that wrist girth of the male handball players is not significantly different is rejected. That is the handballers in this study have very different wrist girth.

The Scheffe post hoc test analysis (table 3) also confirmed that there is significant differences and that there are greater similarities among UAC Benin and Uni-Ghana team players than Uni-llorin handball players who are slightly different and have lowest values of $17.78 \mathrm{~cm}$ in wrist girth. The wrist girth of $18.35 \mathrm{~cm}$ for this group is different from wrist girth of male Grip athletes of $18.02 \pm 0.86$ ( Fallahi and Jadidian (2011)), and 17.7 \pm 0.9 from anthropometry and throwing velocity in elite water polo by specific playing positions by Ferragut, Abraldes, Vila, Rodriguez, Argudo and Fernandes (2011). A robust wrist girth will definitely be an advantage in shooting, passing and catching in handball.

Chest girth (cm): The mean Chest girth for the male handballers is $92.26 \pm 1.06 \mathrm{~cm}$ and a range of $39.5-102.6 \mathrm{~cm}$. The F-ratio of .705 (table 2) is not statistically significant at 0.05 (F$0.05=3.32$ ). The null hypothesis that Chest of the Male handball players is not significantly different is upheld. That is the handballers in this study have very similar Chest girth. That all the players from the West Africa are having relatively the same Chest girth of $92.26 \mathrm{~cm}$,even though the range is from $39.5-102.6 \mathrm{~cm}$. One can therefore assume that any Chest girth from $39.5-102.6 \mathrm{~cm}$ could be ideal to be an elite handball player, since all players are champions from their respective Universities.

Mid-thigh girth (cm): The mean thigh girth for the male handballers is $51.17 \pm 4.97$ and a range of $42.5-61.5 \mathrm{~cm}$. The F-ratio of 7.220 (table 2) is statistically significant at 0.05 (F$0.05=3.32$ ). The null hypothesis that mid-thigh girth of the male handball players is not significantly different is rejected. That is the handballers in this study have very different mid- thigh girth.

The Scheffe post hoc test analysis (table 3) also confirms that there is a significant difference and that there are greater similarities among Uni-Ghana and UACBenin team players than Uni-llorin handball players who are significantly different in mid- thigh girth with the lowest value of $49.26 \mathrm{~cm}$. The mid-thigh girth of $51.17 \mathrm{~cm}$ for this group is difference to the midthigh girth of elite and sub-elite fencers by Tsolakis and Vagenas(2010) with $55.89 \mathrm{~cm} ;$ Rogan,Hilfiker,Clarys,Clijsen and Taeymansa(2011) amateur soccer players with 59.3 \pm 3.8 -TeamA,Team B-58.5 \pm 4.0 ,Team C-61.2 \pm 5.1 ,Team D-58.5 \pm 4.6 . The mid-thigh girth is a measure of muscle mass around the thigh which is necessary for leg strength/power.

From the analysis on table 4 UACBenin male players had the highest values in wrist girth in anthropometric variables. On the other hand, Uni-Ghana had the highest anthropometric variables scores in chest girth, mid-thigh girth. The scheffe post hoc analysis also confirmed that UACBenin and Uni-Ghana are significantly different from the other team in wrist girth, chest girth, mid-thigh. 
Vol. 6, No.2, December 2020, page 26-35

\section{CONCLUSION}

1. There was significant difference in the wrist girth of the University Male championhandballers. UACBenin with $18.88 \mathrm{~cm}$ and follow by Uni-Ghana with $18.35 \mathrm{~cm}$ and Uni-llorin with $17.78 \mathrm{~cm}$.

2. There was no significant difference in the chest girth of the University Male champion -handballers.

3. There was a significant difference in the mid- thigh girth of the University Male champion- handballers. Uni-Ghana with $55.04 \mathrm{~cm}$ and follow by UACBenin with $49.37 \mathrm{~cm}$ and Uni-1lorin with $49.26 \mathrm{~cm}$.

\section{REFERENCES}

Ajayi-Vincent, O. B. (2005) A Comparative Analysis of Somatotype, Body Composition and Performance Characteristics among Elite male Racket Games Players in Nigeria. Unpublished PhD Thesis, University of Ilorin.

Agbonjimi, A. P. (1995). Lower Limb Anthropometrics Characteristics and Endurance Running Performance Time in Young Male Adults. Nigeria Association of Sports Science and Medicine (NASSM); 2, 16-20.

Bale, P. (1991) Anthropometric, Body Composition and Performance Variables of Young Elite Female Basketball Players. Sports Medicine and Physical Fitness. 31 (2): 173177

Baxer-Jones AD, Helms P, Maffulli N, Baines-Preece JC, and Preece M. (1995). Growth and development of Male gymnasts, swimmers, soccer and Tennis players: a longitudinal study. Annals of Human Biology, 22(5), 381-394

Carter JEL, Ackland TR, Kerr DA, and Stapff AB. (2005). Somatotype and size of elite female basketball players. Journal of Sports Sciences, 23(10), 1057-1063.

Carter, JEL, (1982): Body composition of Olympic athletes. Inc. J.E.L. Carter (Ed). Physical Statute of Olympic Athletes. Part 1, Montreal Olympic Games Anthropological Project. Basel: Karger.

Carter, J.E.L. (1970): The Somatotypes of Athletes. A review: human Biology 42:535-569

Damsgaard R, Bencke J, and Matthiesen G. (2000). Is prepubertal growth adversity affected by sport? Medicine and Science in Sports and Exercise, 32(10), 1698-1703.

De Garry A, Levine L, Carter J.E.L. (1974): Genetic and Anthropological studies of Olympic Athletes. New York: Academic Press.

Dominic, O. L. (2006). The relationship between physical characteristics and shooting ability of Kwara State basketball players. Journal of Educational Research and Development. Vol. 1 No. (2) ISSN 0794-4667.

Dominic, O. L. (2011): Kinetic Analysis of Arm Motion during jump shot in Nigerian Female Basketballs. Unpublished PhD Thesis, Ahmadu Bello University, Zaria, Nigerian. 
Gabbett T., Georgieff B., Anderson S., Cotton B., Savovic D., and Nicholson L. (2006). Changes in skill and physical fitness following training in talent -identified volleyball players, Journal of Strength and Conditioning Research, 20(1), 29-35

Gabbett T. J. (2000) Physiological and anthropometric characteristics of amateur rugby league players. British Journal of Sports Medicine, 34, 303-307.

Gorostiaga E. M., Granados C., Ibanez J., \& Izquierdo M. (2005).Differences in physical fitness and throwing velocity among elite and amateur male handball players. International Journal of Sports Medicine, 26(3), 225-232

Gorostiaga E. M., Izquierdo M., Iturralde P., Ruesta M., \& Ibanez J. (1999). Effects of heavy resistance training on maximal and explosive force production, endurance and serum hormes in adolescent handball players. European Journal of Applied Physiology $.80(5), 485-493$.

Granados C., Izquierdo M., Ibanez J., Bonnabau H., \& Gorostiaga E. M. (2007). Differences in physical fitness and throwing velocity among elite and amateur female handball players. International Journal of Sports Medicine, 28(10), 860-867.

Hassan, A. A. A., Rahaman, J. A., Cable, N. T. and Reilly, T. (2007): Anthropometric Profile of Elite Male Handball Players in Asia. Biology of Sport, Vol.24, No.1, 2007

Hirata, Kin-Itsu (1966): Physique and Age of Tokyo Olympic Champions. Journal of Sports Medicine \& physical Fitness. 6:207

Lidor R., Falk B., Arnon M., Cohen Y., \& Segal G. (2005): Measurement of talent in team handball. Journal of Strength and conditioning Research, 19(2), 318-325

Maffulli N., Kings B. J., \& Helms P. (1994). Training in elite young athletes the training of young athletes (TOYA) study]: injuries, flexibility and isometrics strength, British Journal of Sports Medicine, 28 (2), 123-126

Mahmoud, A.I., (2005): Encyclopedia of the determinants of Sports training theory and practice of planning training programs sport of karate. Center of Book Publishing, Alexandria, pp:90-91

McGee K. J., \& Burkett L. N. (2003). The National football League combine; a reliable predictor of draft status? J Strength Cond Res, 17(1), 6-11

McIntyre M. C. (2005); A comparison of the physiological profiles of elite Gaelic footballers, hurlers, and soccer players. Br J Sports Med, 39 (7), 437-439

McIntyre M. C., \& Hall M. (2005). Physiological profile in relation to playing position of elite college Gaelic footballers. Br J Sports Med, 39 (5), 264-266

Moncef C, Said M, Olfa N, Dagbaji G. Influence of morphological characteristics on physical and physiological performances of Tunisian elite male handball players. Asian $\mathbf{J}$ Sports Med, 2012; 3(2): 74- 80

Meir, R., Newton R, Curtis E, Fardell M, Butter B (2001): Physical Fitness qualities of Professional Rugby League Football Players: Determination of positional differences. Journal of Strength and Conditioning Research / National Strength \& Conditioning Association, 15, 450-458. 
Norton K. \& Olds T. (1996) Anthropometrical: a textbook of body Measurement for sports and health courses. Sydney: University of NSW Press.

O’Connor, D.(1996) Physiological Characteristics of Professional Rugby League players. Strength \& Conditioning Coach, 4, 21-26.

Reilly, T., Bangsbo, J., Franks, A. (2000a): Anthropometric and Physiological Predispositions for Elite soccer. J Sports Sci. 18:669-683

Sharma, S.S., Dixit N.K. (1985): Somatotype of Athletes and their Performance. International Journal of Sports Medicine. 6, 161-162

Tanner, J.M. (1964): The Physique of the Olympic Athletes London Allen and Urwin.

Toriola, A. (1999): Protocol on Judo. Sports Information and Science and Agency. (SISA Protocol) 1-36.Pretoria.

Toriola A. (1999): Table-tennis, Tennis, Badminton, Handball, Judo, Volleyball. SISA Protocols: Pretoria: SISA.

Ugarkovic D., Matavulj D., KuKolj M., Jaric S. (2002). Standard anthropometric, body composition and strength variables as predictors of jumping performance in elite junior athletes, Journal of Strength and Conditioning Research, 16(2), 227-230.

Van den Tillaar R. (2004). Effect of different training programs on the velocity of over-arm throwing; a brief review. Journal of Strength and Conditioning Research, 18 (2), 388396.

Vila H, Manchado C, Rodriguez N, Abraldes JA, Alcaraz PE, Ferragut C. Anthropometric profile, vertical jump, and throwing velocity in elite female handball players by playing positions. J Strength Cond Res, 2012; 26(8): 2146-2155

Young, R. W. (2003). Evolution of the human hand: the role of throwing and clubbing. Journal of Anatomy 202 (1) 165-174

Xu, C.F., Chen, L.N. (2000): The study on characteristics of Physical Capacities in Elite Single Female aerobic Athletes. Journal of Physical Education, 127, 120-122

Ziv G, Lidor R. Physical characteristics, physiological attributes, and on-court performances of handball players: A review. Eur J Sport Sci, 2009; 9(6): 375-386 